\title{
GROWTH AND SOME SURFACE CHARACTERIZATION OF TIN SULPHIDE (SnS) THIN FILM BY TWO-ELECTRODE CELL ARRANGEMENT FOR PHOTO ABSORPTION
}

\author{
*Lasisi A. R. ${ }^{1,2}$, Alabi, A. B. ${ }^{2}$,Taleatu, B. A. ${ }^{3}$ and Babalola, O. A. ${ }^{4}$ \\ ${ }^{1}$ Department of Physics, Federal College of Education, Kontagora, Nigeria. \\ ${ }^{2}$ Department of Physics, University of Ilorin, Ilorin, Nigeria. \\ ${ }^{3}$ Department of Physics \& Engineering Physics, Obafemi Awolowo University Ile-Ife, Nigeria. \\ ${ }^{4}$ Physics Advanced Laboratory, SHESTCO, Sheda, Abuja, Nigeria. \\ * Corresponding author: lasisiar@yahoo.com (+234-8058228941) \\ (Received: $10^{\text {th }}$ May, 2020; Accepted: $21^{\text {st }}$ May, 2021)
}

\section{ABSTRACT}

This study presented deposition of tin sulphide ( $\mathrm{SnS}$ ) thin film using a two-electrode electrochemical cell arrangement. The bath electrolyte comprised tin sulphate $\left(\mathrm{SnSO}_{4}\right)$, hydrated sodium thiosulphate $\left(\mathrm{Na}_{2} \mathrm{~S}_{2} \mathrm{O}_{3}\right.$ $\left.\cdot 5 \mathrm{H}_{2} \mathrm{O}\right)$ and sulphuric acid $\left(\mathrm{H}_{2} \mathrm{SO}_{4}\right)$. The acid was used to adjust the $\mathrm{pH}$ of the bath. The deposited film was characterised using Surface Profilometer, X-Ray Diffractometer (XRD), Uv-Visible Spectrophotometer and four point probe technique. Surface profiling revealed that the film is continuous with thickness of about $60 \mathrm{~nm}$. The XRD result showed that the film has orthorhombic crystal structure. Film's crystallite size was estimated as $0.61 \mathrm{~nm}$ and interplanar spacing as $0.29 \mathrm{~nm}$. The Uv-visible Spectrophotometer result reveals that, the film has good absorbance but poor reflectance and transmittance in the visible light region. The film has direct allowed transition with energy band gap of $1.69 \mathrm{eV}$. Values of surface resistivity and conductivity were deduced from data obtained from Four-point probe studies as $5.12 \times 10^{-4} \Omega$-cm and $1.96 \times 10^{3} \Omega^{-1} \mathrm{~cm}^{-1}$ respectively. The I-V characteristics curve of ITO/SnS/Ag structure is linear indicating an Ohmic contact between the substrate electrode and the deposited layer. It can therefore be suggested that the film can allow pathway for photoabsorption and also aid charge transfer in photovoltaic process.

Keywords: tin sulphide, orthorhombic, electrochemical deposition, characterization, photovoltaic and surface resistivity.

\section{INTRODUCTION}

Production of affordable energy from renewable source is a necessity in this era of high energy demand. Photovoltaic technology (PV) has been recognised as a promising energy supply option but it is economically unviable because of the cost of electricity produced by PV cells. This cost implication can be reduced by either improving the efficiency of the cell and/or by drastically reducing the fabrication cost. This can be achieved with thin film solar cells designed for little quantity of starting material as well as less costly processing technique. Solar cell fabricated from $\mathrm{CuIn}(\mathrm{Ga}) \mathrm{Se}_{2}$, CdTe, GaAs and crystalline silicon (c-Si) absorber material have attained high efficiency above $23 \%$ (Hedge et. al., 2011). Its challenges are scarcity of indium and gallium, and toxicity of cadmium and other substances (Busari et al., 2020). Thus, there is a need for materials that are abundant, stable to ambient condition and environmentally benign to produce relatively cheap devices. One of such materials is tin sulphide ( $\mathrm{SnS}$ ). It is a group IV-VI compound semiconductor material having direct allowed energy band gap near $1.3 \mathrm{eV}$ and high absorption coefficient $\left(\alpha>10^{4} \mathrm{~cm}^{-1}\right)$ (Koteeswara Reddy et. al., 2006). Its constituent elements Sn and $\mathrm{S}$ are abundant and are less toxic. $\mathrm{SnS}$ has ptype electrical conductivity and it has theoretical light conversion efficiency nearer to $25 \%$ according to Loferski diagram (Loferski, 1956). Ghosh et. al., (2009) opined that with better understanding of materials' growth concept and optimisation of the device design, solar cell based on $\mathrm{SnS}$ thin film structure with efficiency greater than $10 \%$ is achievable. Therefore, preparation of SnS thin film by electrochemical deposition process and some surface characterization to understand its suitability for photovoltaic device application are contents of this report.

\section{EXPERIMENTAL}

Tin sulphide (SnS) thin films were deposited from solution using a two-electrode electrochemical cell arrangement earlier reported in one of our previous studies (Taleatu et. al., 2011). The substrate (working electrode) was indium tin oxide 
(ITO) coated glass pieces. The starting materials for preparing the electrolytic bath were tin sulphate $\left(\mathrm{SnSO}_{4}\right)$ and hydrated sodium thiosulphate $\left(\mathrm{Na}_{2} \mathrm{~S}_{2} \mathrm{O}_{3} 5 \mathrm{H}_{2} \mathrm{O}\right)$. Dilute sulphuric acid $\left(\mathrm{H}_{2} \mathrm{SO}_{4}\right)$ was used to adjust the $\mathrm{pH}$ of the bath. They were all analytical grade sourced from sigma-Aldrich and they were used as received without further purification. The dissolving reagent was distilled water. Firstly, little quantity of tin sulphate $(25 \mathrm{ml}, 0.01 \mathrm{M})$ was introduced into glass cell to which sodium thiosulphate solution $(25 \mathrm{ml}, 0.05 \mathrm{M})$ was also immediately added. Few drops of sulphuric acid $(5 \mathrm{ml}, 0.05 \mathrm{M})$ were added to the solution. Both the counter electrode (graphite piece) and the working electrode (Clean ITO) were connected to the power supply and a cathodic voltage of $0.9 \mathrm{~V}$ was selected to run the experiment for about 39 minutes. The film was removed, rinsed thoroughly with distilled water and briefly dried on hot plate and kept with a sample holder in a desiccator. Surface Profilometer was used to determine the thickness of the film as well as its surface roughness. Film's crystallinity was studied using X-Ray Diffractometer (XRD). Optical properties were obtained using Uv-Visible spectrophotometer while the electrical properties were determined using four point probe technique with Keithley source meter, laboratory tracer and interactive characterization software packages.

\section{RESULTS AND DISCUSSIONS}

\section{Layer thickness and surface roughness}

The surface roughness and average thickness of the deposited film were examined with Surface
Profilometer. Image of the profiled surface is shown in Fig.1. It can be observed that the distribution of the film's particles is continuous across the substrate's surface. Few observed intense peaks at some data points on abscissa suggest intermittent surface roughness which challenges the uniformity, but the pattern of the distribution clearly implies that the deposited SnS thin film does not have pin-hole. The film adheres firmly to the substrate's surface. Average layer thickness is given as $0.06 \mu \mathrm{m}$.

\section{Film's crystallinity}

The structure of SnS thin film was determined by $\mathrm{X}$-Ray Diffractometer. The diffraction pattern is presented in Fig. 2. Prominent diffraction peaks attributable to reflections from planes of crystalline $\mathrm{SnS}$ structure were observed at Bragg's angle $2 \theta$ of $30.64,32.03$ and $63.83^{\circ}$. According to the report of Gosh et al., (2010), the observed peaks are designates of orthorhombic crystal structure of SnS lattice. No other peaks can be attributed to the deposited film except the substrates materials. This suggests that the film exhibits good crystal properties including phase purity (Adewinbi et al., 2021). Inter-planar spacing of the film was determined as $0.29 \mathrm{~nm}$ while crystalline size, D, was estimated from the most prominent peak to be $0.61 \mathrm{~nm}$ using the standard relation (Debye-Scherer's formula) given in Eq. 1. Where $\lambda$ is the wavelength of the incident $\mathrm{CuKa}$ radiation (1.5406 $\AA$ ), $\beta$ is the peak's full width at half maximum and $\theta$ is the diffracting angle.

$D=\frac{0.9 \lambda}{\beta \cos \theta}$ 


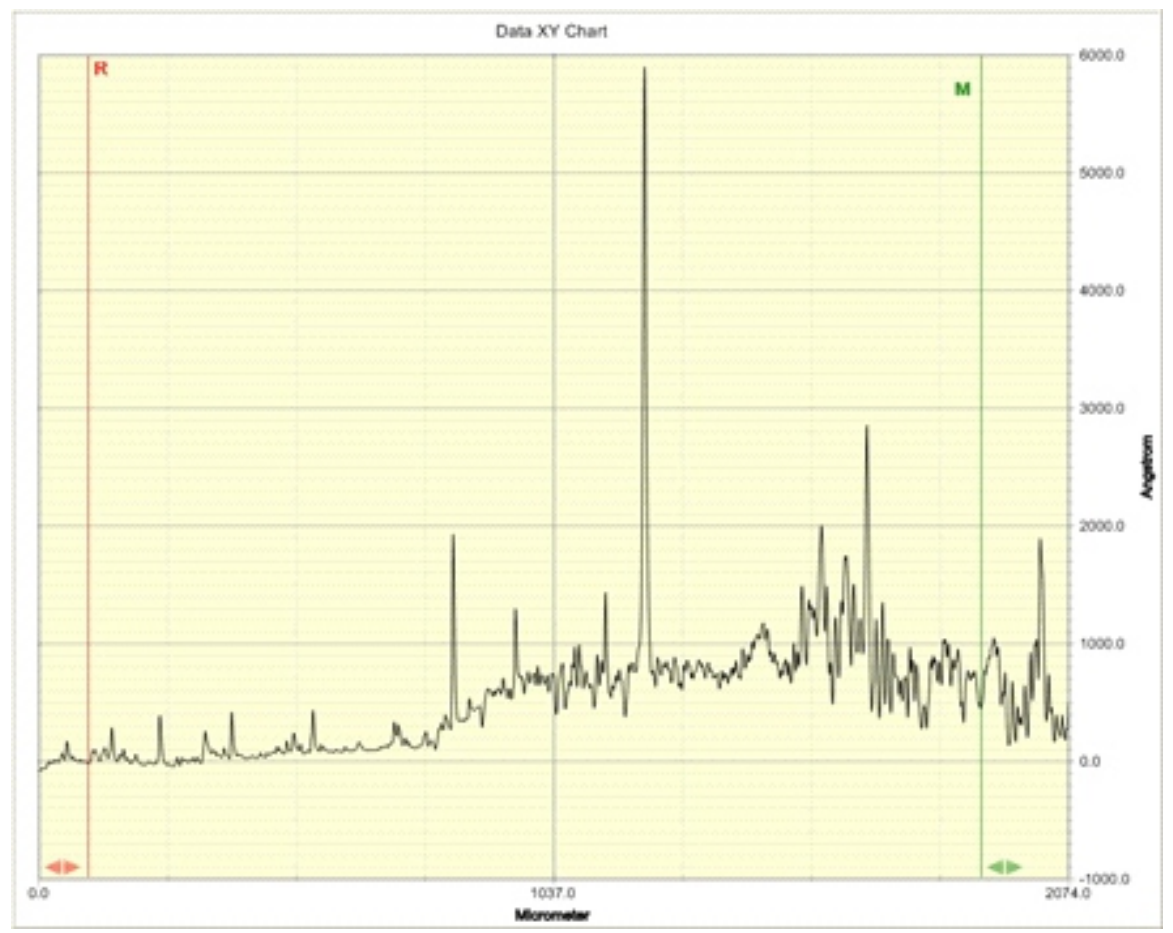

Fig.1. Surface profile image of the Sns thin film

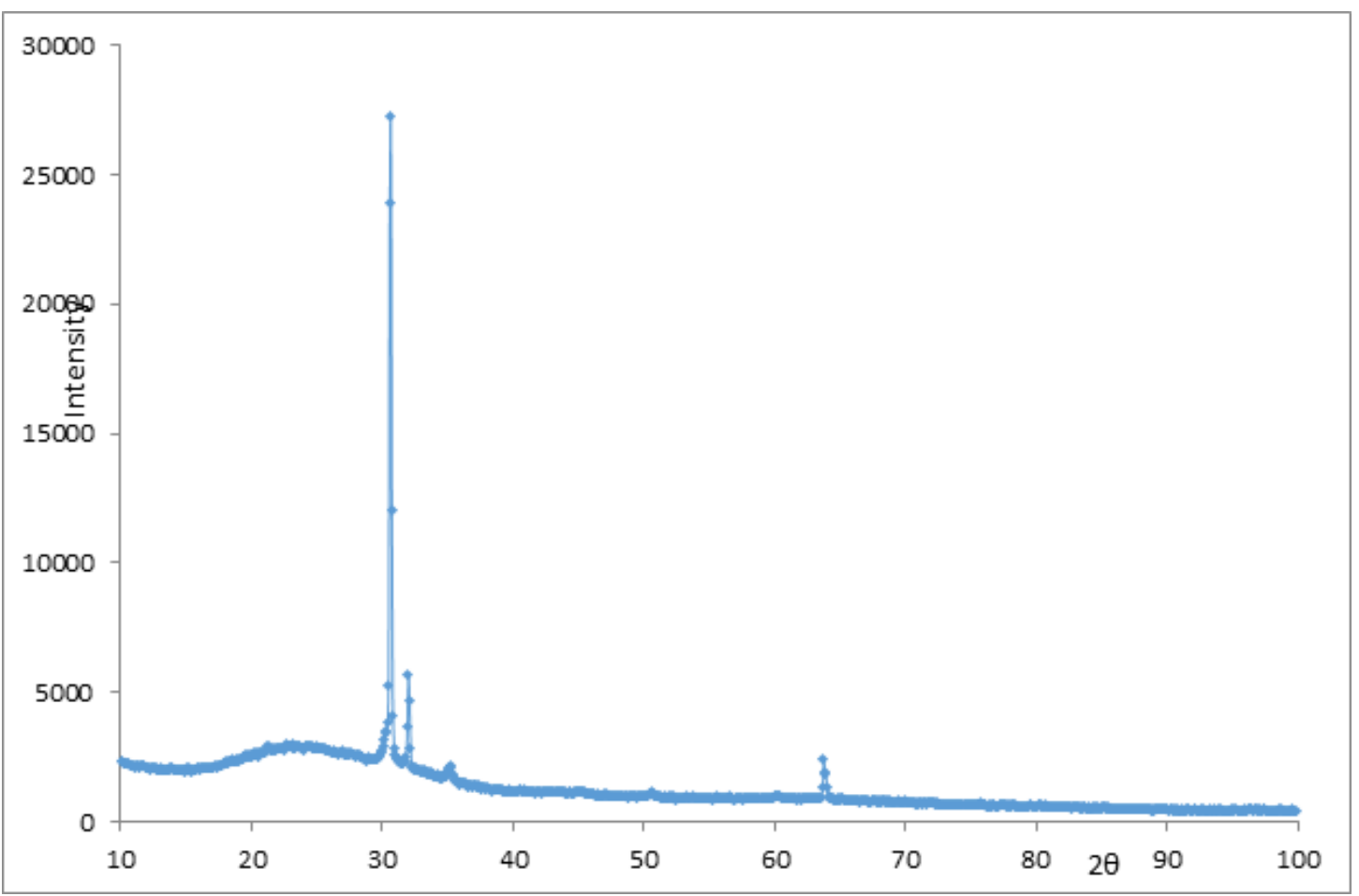

Fig.2 XRD PATTERN OF SnS THIN FILMS

\section{Opticalproperties}

Film's response to light was understood by exposure to incident beam from $\mathrm{Uv}_{\mathrm{v}} \mathrm{Visible}$ spectrophotometer in the wavelength range from 290 to $900 \mathrm{~nm}$. Spectral data in the visible region was analysed to understand absorptance and energy band transition. Figures 3, 4 and 5 present the film's transmittance, absorbance and reflectance respectively. From the graphs, it can be seen that the percentage transmittance is less than $10 \%$ while the percentage of absorbance is well above $65 \%$ and reflectance is around $20 \%$. This 
implies that the deposited SnS thin film is a good absorber of visible light but a poor transmitter and reflector. This is in agreement with the report by Ghosh et. al., 2010.

Energy band transition of the film was determined from Tauc model. Absorption coefficient, $\alpha$, was first generated from the measured optical data according to the relation below.

$\alpha=-\frac{1}{d} \ln T$

The absorption coefficient was then related to the incident photon energy $(b v)$ using Tauc's model expression below.

$\alpha=A\left(h v-E_{g}\right)^{n / 2}$

Where $\mathrm{A}$ is an empirical constant often called band tail parameter. It is independent of the photon energy $(h v) . E_{g}$ is the energy band gap, it is often found near the mobility edges and between the localized states, and $n$ is the photon transition mode power factor. It is 1 or 4 for direct and indirect allowed transition respectively. Value of energy band gap of sample is estimated by plotting $\alpha^{2}$ against the incident photon $(b v)$. The linear portion of the plot is extrapolated to the photon energy axis (abscissa) where $\alpha^{2}=0$ (Adewinbi et al., 2021). From the plot in Figure 6, a direct optical energy band gap of $1.69 \mathrm{eV}$ was estimated for the film. This value falls within the range of values of energy gap (1.2-1.7 eV) reported for SnS thin film in the literatures (Ogah et. al., 2009, Ghosh et. al., 2010, Hedge et. al., 2011, and Santhosh-Kumar et. al., 2013). Thus, thin film materials with high absorbance in the visible region and optical band gap near to optimum direct interband edges can serve as a good candidate in the development of effective absorber layer of hetero-junction photovoltaic cells (Busari et al., 2020).

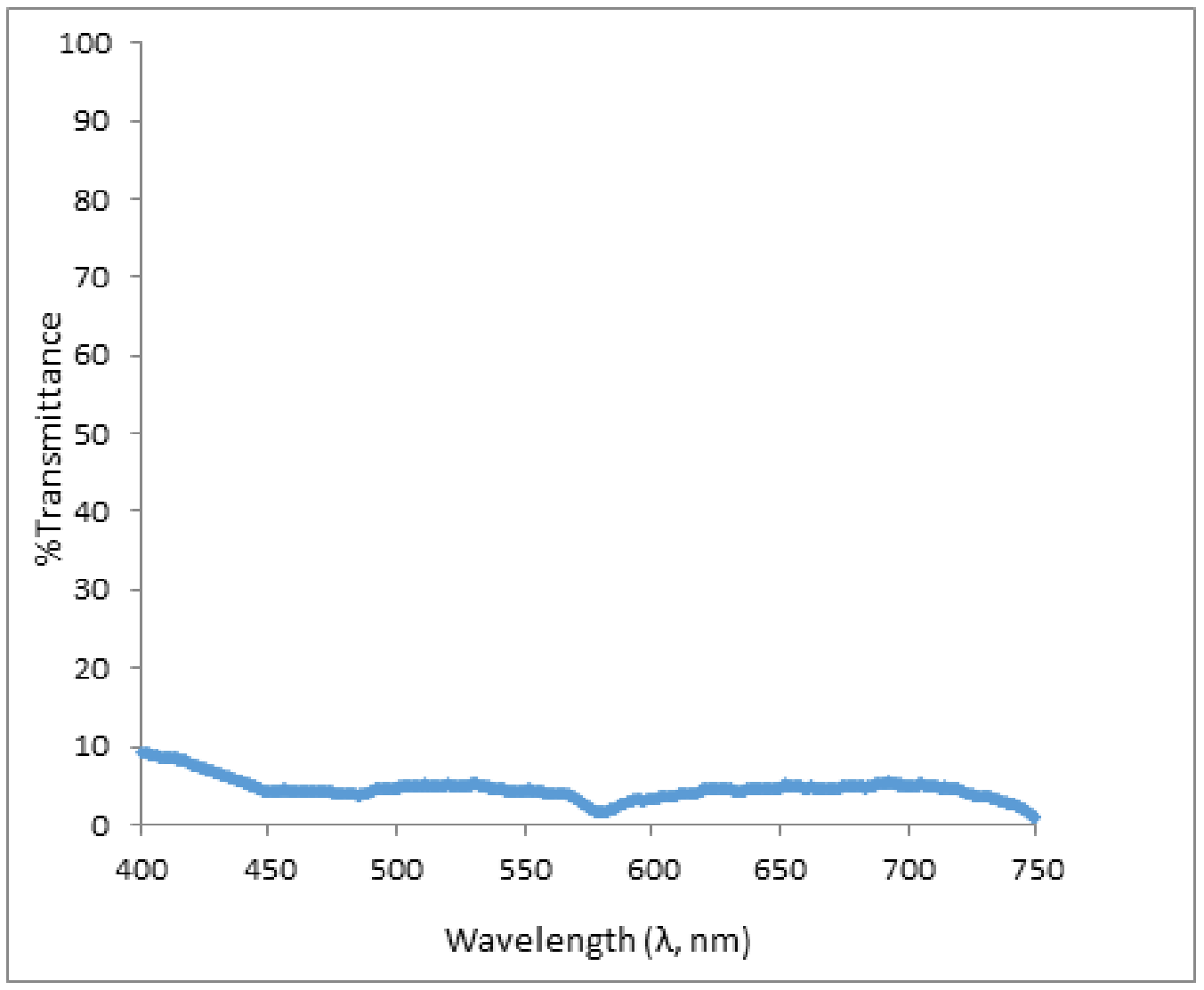

Fig.3. Film's transmittance across visible region 


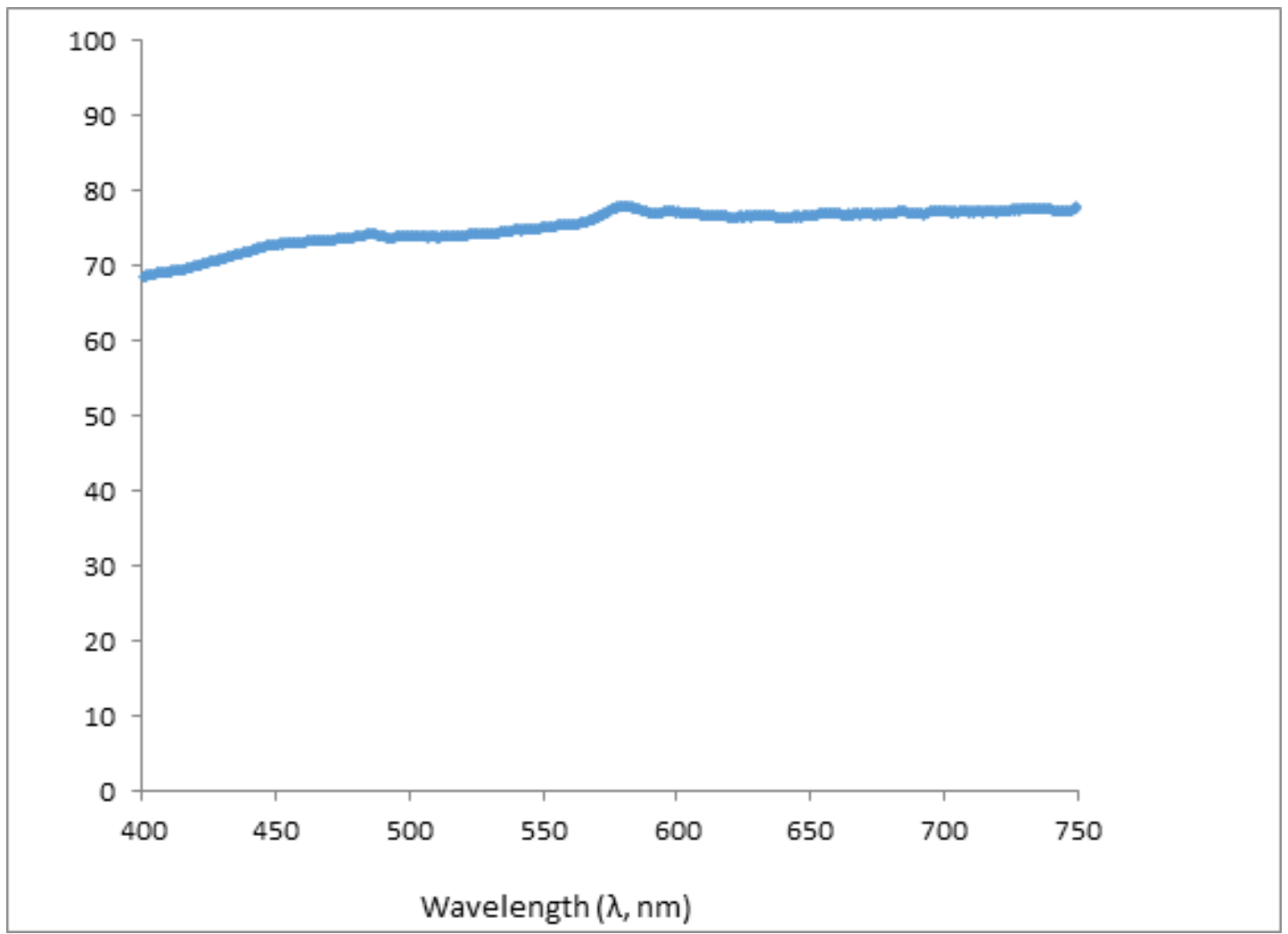

Fig.4 Graph of Absorbance against Wavelength

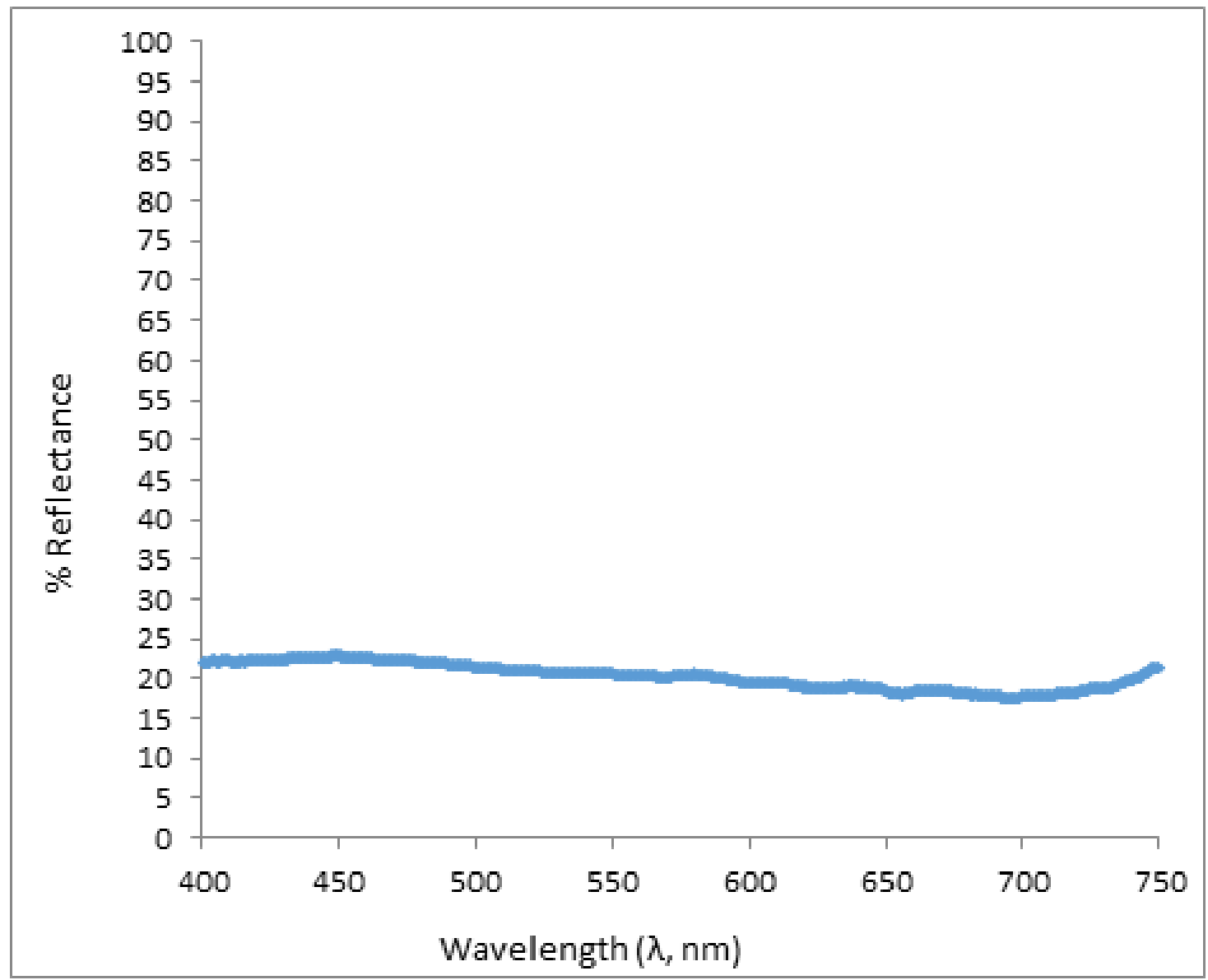

Fig.5. Film's reflectance in the visible wavelength region 


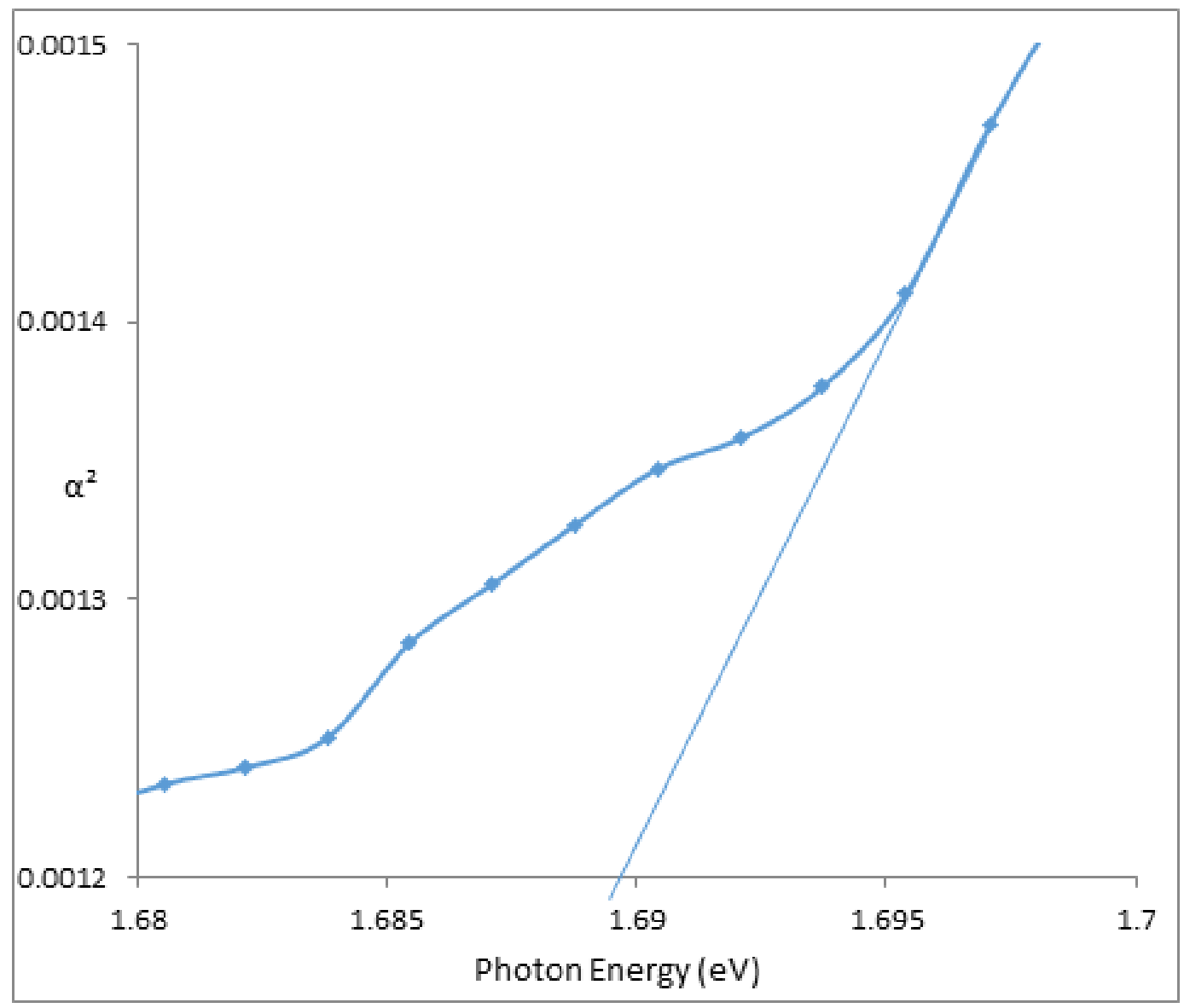

Fig.6. Energy band gap of the deposited SnS thin film

\section{Electrical characterization}

The electrical properties of the deposited SnS film were studied using four points probe in collinear array mode with Keithley source metre. Thin silver paste was coated on the film to establish contact with the probe tips. The data was analysed with interactive laboratory tracer software. Current-Voltage (I-V) characteristics curve of the ITO/SnS/Ag structure is shown in Figure 7. It is a near straight line pattern which implies that the junctions between ITO/SnS and $\mathrm{SnS} / \mathrm{Ag}$ are ohmic (Busari et. al., 2020). This is consistent with the reports from Sato et. al., (2005) and Ghosh et. al., (2010) which established ohmic contact from indium and gold metallisation. From the value of sheet resistance, surface resistivity and conductivity were calculated by these relations.

$$
R_{\text {Shest }}=4.53\left(\frac{V}{I}\right)
$$

$\rho=t R_{\text {Shest }}$

$R_{\text {Shest }}$ is the sheet resistance, $V$ is the voltage, I is current and $\frac{V}{I}$ is determined from the slope, $t$ is the film's thickness and $\rho$ is probe resistivity. Thus, the surface resistivity and the conductivity of the film were obtained as $5.106 \times 10^{-4} \Omega \mathrm{cm}$ and $1.958 \times 10^{3}$ $\Omega^{-1} \mathrm{~cm}^{-1}$ respectively. This suggests that the grown $\mathrm{SnS}$ thin film can be a good conductor of electricity. 


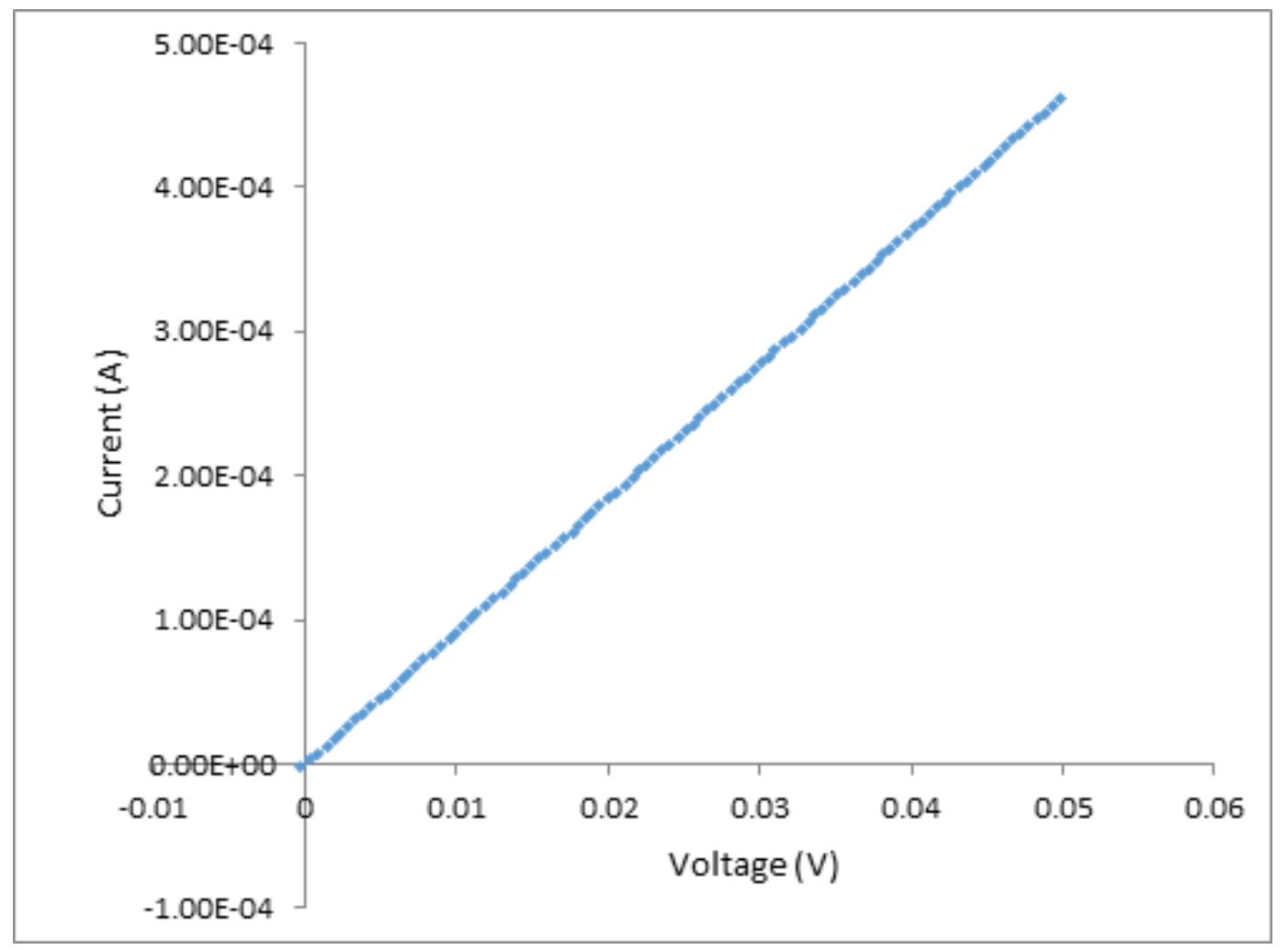

Fig.7. I-V Characteristics of ITO/SnS/Ag Structure

\section{CONCLUSION}

Two-electrode cell arrangement has been used to deposit SnS thin films on ITO glass coated substrate from inorganic solution electrolyte. The growth was carried out at room temperature and the use of supporting electrolytes or catalysts which usually leave remnant impurities in the solution was avoided. The deposited film's particles are evenly distributed across the substrate's surface. The film shows high percentage absorbing capability of visible light and narrow optical band gap energy coupled with good conductivity. The SnS film can be suggested as a good recipe in the fabrication of absorber layer of hetero-junction thin film solar devices.

\section{REFERENCES}

Adewinbi S.A, Busari R.A, Adewumi O.E and Taleatu B.A (2021) Effective photoabsorption of two-way spin-coated metal oxides interface layers: surface microstructural and optical studies. Surfaces and Interfaces 23, 101029 (1-10).

Busari R.A, Taleatu, B.A, Adewinbi S.A, Adewumi O.E, Omotoso E, Oyedotun K.O and Fasasi A.Y (2020) Synthesis and surface characterization of electrodeposited quaternary chalcogenide $\mathrm{Cu} 2 \mathrm{Zn} x \mathrm{Sn} y \mathrm{~S} 1+x+2 y$ thin film as transparent contact electrode. Bull. Mater. Sci. 43, 831-9

Chopra K. L., P. D. Paulson, V. Dutta, (2004) ThinFilm Solar Cells: An Overviewll, Prog Photovolt: Res. Appl., 12; 69-92.

Ghosh, B., M. Das, P. Banerjee, S. Das (2009) Fabrication of the $\mathrm{SnS} / \mathrm{ZnO}$ Heterojunction for PV Applications using Electrodeposited ZnO Films. Semicond. Sci. Technol. 24, 1-7.

Ghosh B., R. Roy, S. Chowdhury, P. Banerjee and S. Das (2010) Synthesis of SnS thin films via galvanostatic electrodeposition and fabrication of $\mathrm{CdS} / \mathrm{SnS}$ heterostructure for photovoltaic applications. Applied Surface Application. 256, 4328-4333.

Hegde S. S., A.G. Kunjomana, K. Ramesh, K.A. Chandrasekharan, M. Prashantha (2011) Preparation and Characterization of $\mathrm{SnS}$ Thin Films for Solar Cell Application International Journal of Soft Computing and Engineering (IJSCE) 1, IssueNCRAMT2011.

Koteeswara R. N., K. Ramesh, R. Ganesan, K.T.R. Reddy, K.R. Gunasekhar, E.S.R. Gopal, 
(2006) Synthesis and characterization of co-evaporated tin sulphide thin films. Applied Physics A., 83, 133-138.

Loferski J. J. (1956) Theoretical Considerations Governing the choice of the Optimum Semiconductor for Photovoltaic Solar Energy Conversion. Journal of Applied Physics, 27, 7, 777-784.

Ogah E. Ogah, Guillaume Zoppi, Ian Forbesand R.W. Miles (2009) Thin films of tin sulphide for use in thin film solar cell devices. Thin solid films. 517, 2485-2488.

Santhosh-Kumar, K., Manoharan, C., Dhanapandian, S and Gowri Manohari, A (2013). Physical Investigation on Spray Deposited Tin Sulphide Thin films.
International Journal of Current Material Sciences. 1, 2,15-17.

Sato, N, Ichimura, M, Arai, E and Yamazaki, Y (2005) Characterization of electrical properties and photosensitivity of $\mathrm{SnS}$ thin films prepared by the electrochemical deposition method. Solar energy materials and solar cells. 85, 153-165.

Taleatu B. A., A.Y. Fassasi, G.Di Santo, S. Bernstorff, A. Goldoni, M. Fanetti, L. Floreano, P. Borghetti, L. Casalis , B. Sanavio and Castellarin-Cudia (2011) Electro-chemical deposition of zinc oxide nanostructures by using two electrodes. AIP Advances 1, 032147 